\title{
Si-fitólitos em Eudicotiledôneas e seu potencial na descontaminação de solos contendo metais pesados
}

\author{
Heloiza Márcia Fernandes Horn \\ Adolf Heinrich Horn ${ }^{2^{*}}$ \\ Regynaldo Arruda Sampaio ${ }^{3}$ \\ Márcio Neves Rodrigues ${ }^{3}$ \\ Anarelly Costa Alvarenga \\ Igo Fernando Lepsch ${ }^{3}$ \\ ${ }^{1}$ Autônoma \\ Rua Monte Castelo, 156 \\ Belo Horizonte MG Brasil \\ CEP 31.710-070 \\ ${ }^{2}$ Universidade Federal de Minas Gerais \\ Instituo de Geociências \\ Departamento de Geologia \\ Av. Antônio Carlos, 6627 \\ Belo Horizonte MG Brasil \\ CEP 32901-000 \\ ${ }^{3}$ Universidade Federal de Minas Gerais \\ Instituto de Ciências Agrárias \\ Campus Regional Montes Claros \\ Bairro Universitário \\ Montes Claros MG Brasil \\ CEP 39404-547 \\ ${ }^{*}$ Corresponding Author: \\ hahorn@ufmg.br
}

\begin{abstract}
RESUMO
Para a descontaminação de solos com metais pesados são propostos diversos métodos e procedimentos. Dentre eles, tem-se a fitorremediação. O presente estudo investiga a fitorremediação por fitólitos. Neste texto foram investigadas três plantas nativas do bioma Cerrado com capacidade de produzir sílico-fitólitos. As plantas estudadas foram: Rollinia leptopetala, Piptadenia gonoacantha e Sida sp. Os resultados revelaram que as espécies estudadas concentraram metais pesados nos sílico-fitólitos em concentrações diferentes para os órgãos (raízes, caules, folhas) das plantas. A concentração nas plantas aumenta com a maior concentração disponível no solo. Si-fitólitos extraídos do solo (com pequenas quantidades de outros compostos, como óxidos; argilas < 1-3\%) mostram concentrações médias comparáveis às concentrações médias das plantas estudadas. Assim, os metais disponíveis são transformados em metais não-disponíveis, o que permite o uso destas plantas para a descontaminação.
\end{abstract}

Palavras-chave: fitorremediação, contaminantes, opala orgânico, contaminação do solo, plantas nativas

\section{ABSTRACT}

For the decontamination of soils, rich in heavy metals are proposed various methods and procedures. Among them, one is the phytoremediation. The present study investigates the phytoremediation by phytoliths. In this text three native plants from the Cerrado biome with ability to produce Siphytoliths, were investigated. The studied plants are Rollinia leptopetala, Piptadenia gonoacantha and Sida sp. The results showed that the studied species concentrated heavy metals in Si-phytoliths in different concentrations in their organs (leaves, stems, roots). The concentration in plants increases with the highest available concentration in the soil. Si-phytoliths extracted from the soil (with small amounts of other compounds such as oxides, clays $<1-3 \%$ ) show concentrations comparable to average concentrations of the studied plants. Thus, the available metals are transformed into non-available ones, which allows the use of these plants for decontamination.

Keywords: phytoremediation, contaminants, organic opal, soil contamination, native plants

\section{INTRODUÇÃO}

As atividades antrópicas vêm contribuindo cada vez mais para o aumento das concentrações de metais pesados nos ecossistemas. Esses metais ocorrem normalmente em quantidades diminutas no ambiente, o que permite classificá-los como elementos traços.

Os solos são considerados como um compartimento muito específico na biosfera. Isso não só porque é um dos depósitos finais de contaminantes, mas também por agir como tampão natural no controle do transporte de elementos químicos e substâncias para a hidrosfera, a atmosfera e biota, e vice-versa.

Diversos procedimentos têm sido propostos para minimizar os efeitos negativos das altas concentrações de 
metais pesados nos ecossistemas, como, por exemplo, as técnicas de biorremediação. Dentre essas técnicas, a fitorremediação tem sido utilizada para mitigar solos em minerações, indústrias etc. Além de eficiente, a fitorremediação é uma tecnologia ecologicamente correta e tem boa aceitação pelo público. Dentre as diversas modalidades de fitorremediação destacam-se: rizoextração, fitoextração, fitotransformação, fitoestabilização, fitovolatilização e fitorremediação por fitólitos. Esse trabalho aborda a fitorremediação por fitólitos, utilizando-se plantas nativas do bioma Cerrado.

Os fitólitos são corpos silicosos microscópicos, amorfos, que resultam de processos nos quais algumas plantas superiores depositam sílica intra e extracelular após absorvê-la da solução do solo. Após a morte das plantas e sua decomposição, os Si-fitólitos existentes em sua constituição depositam-se no solo.

\section{MATERIAL E MÉTODOS}

\subsection{DESCRIÇÃO DA ÁREA}

A área do trabalho é limitada pelas coordenadas UTM 702600E - 702300E e $8230750 \mathrm{~N}-8230350 \mathrm{~N}$, com uma extensão de aproximadamente $500 \mathrm{~m}^{2}$, localizada a sudoeste da cidade de Riacho dos Machados, MG, e a nordeste da Mineração Riacho dos Machados, subsidiária da empresa Carpathian Gold Inc. Nessa área ocorrem zonas de influência hidrotermal durante o Pré-Cambriano com alto teor de $\mathrm{Zn}, \mathrm{Pb}$ e $\mathrm{Cu}$, entre outros metais, ligados a processos da formação dos depósitos de $\mathrm{Zn}$ e Au da região (IBGE, 2015).

As rochas e os solos formados têm concentrações altas de metais pesados disseminados e em concentrados ao longo de zonas de falhas específicas, ultrapassando localmente os valores

\subsection{TRABALHO DE CAMPO}

As amostras georreferenciadas (GPS; altímetro; erro $<3 \mathrm{~m}$ ) foram coletadas em nove pontos ao longo de uma linha NW-SE (Figura 1), representados por três perfis
As plantas, notadamente as pertencentes à família Poaceae, são as principais acumuladoras de silíco-Fitólitos e produtoras de biominerais. O silício é depositado em toda a planta, mas, principalmente nas folhas e, então, é convertido em pequenos grânulos, denominados fitólitos. Dentre outras funções, os fitólitos imobilizam os metais pesados no interior de suas estruturas e diminuem a sua toxidez, evitando ou retardando a sua disponibilização para os ecossistemas, reduzindo assim a contaminação dos seres vivos com metais pesados (FERNANDES-HORN et al., 2016).

O objetivo deste trabalho foi determinar a concentração de metais pesados no solo e em Si-fitólitos de plantas crescidas em área contendo teores elevados desses elementos e, assim, averiguar o potencial dessas espécies para o uso na fitorremediação de solos contaminados.

estabelecidos pela legislação ambiental vigente no Brasil (CONAMA, 2009).A superfície da área é formada principalmente por solos de argilito, arenito e em pequena quantidade por afloramento de gnaisses graníticos do embasamento e veios quartzíticos. A serapilheira é praticamente inexistente. Os solos predominantes na região pertencem as Ordens Argissolo e Cambissolo, cujas fases de relevo majoritárias são: ondulado e forte ondulado EMBRAPA (2004); EMBRAPA (2006).A vegetação natural predominante é a do Cerrado e da Floresta Estacional Decidual e a região pode ser caracterizada como ecótona (LIMA et al., 2012). 
uma amostra de plantas, composta por 1020 indivíduos. A Figura 1 é composta pelas subfiguras: Figura 1A. - Mapa com isolinhas de $\mathrm{Cu}$; Figura 1B- Mapa com isolinhas de $\mathrm{Zn}$ e Figura 1C- Mapa com isolinhas de $\mathrm{Pb}$. As informações apresentadas na Figura 1 foram obtidas nos acervos da Mineração Riacho dos Machados, subsidiária da empresa Carpathian Gold Inc. e no aplicativo Google Maps, 2015. Foram identificadas cinco espécies da Classe Eudicotiledôneas, potenciais formadoras de fitólitos, típicas do Bioma Cerrado e que ocorrem na área de pesquisa; a citar Rollinia leptopetala (Familia Annonaceae), Piptadenia gonoacantha (Família Fabaceae), Sida sp (Família Malvaceae), Senna obtusifolia (Família Fabaceae) e Solanum capsicoides (Família Solanaceae), das quais as duas últimas foram descartadas devido a sua sazonalidade.

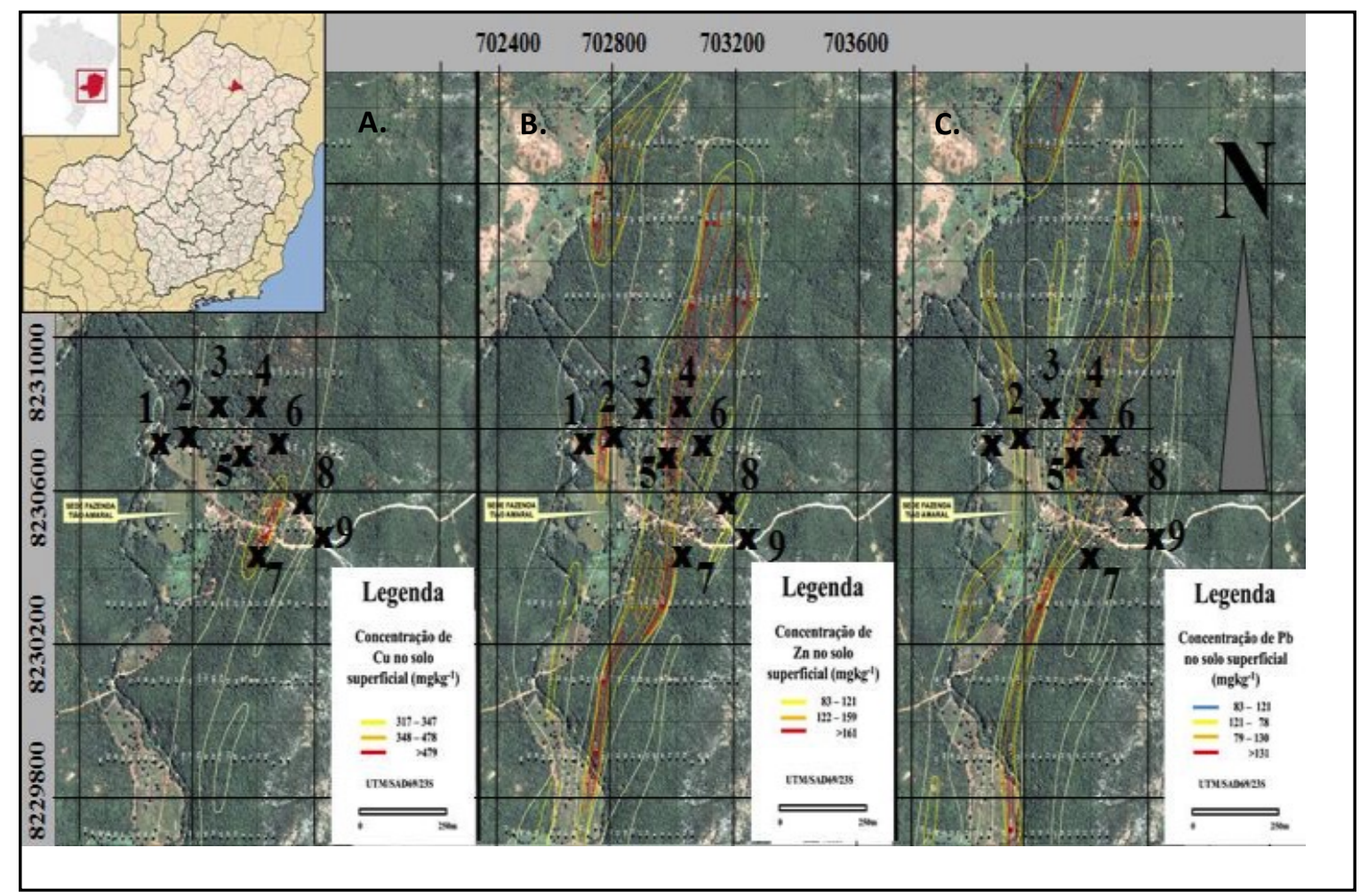

Figura 1 Mapas com isolinhas da concentração dos metais pesados e os nove pontos da amostragem.

\subsection{PREPARAÇÃO DAS AMOSTRAS}

\subsubsection{EXTRAÇÃO DE SI-FITÓLITOS NAS AMOSTRAS DE PLANTA}

Após a coleta dos órgãos vegetais, procedeu-se a lavagem do material. Foram efetuadas 5 lavagens, sendo a primeira em água corrente e as demais em água destilada. Em seguida o material já identificado foi levado para secagem em estufa a $65{ }^{\circ} \mathrm{C}$ durante $4-5$ dias. As amostras foram finamente trituradas em moinho do tipo facas e, em seguida, acondicionadas em sacos de papel para, posteriormente, serem depositadas em cadinhos e pesadas em balança analítica. A calcinação das amostras foi feita em mufla a $530{ }^{\circ} \mathrm{C}$ durante 6 horas (STEWART; ARTHUR, 1935; JONES; HANDRECK, 1967; PIPERNO; PEARSALL, 1993).

A extração dos Si-fitólitos das amostras de plantas foi feita pelo Método Parr et al. (2005). O material calcinado foi transferido para tubos de Falcon. Após a adição do material calcinado no tubo, pesou-se novamente o conjunto. A quantidade de amostra calcinada utilizada foi de $1,2 \mathrm{~g}$ em média. Foram adicionados 
$10 \mathrm{ml}$ de $\mathrm{HCl}$ a $10 \%$ ao material. Os recipientes foram aquecidos em banhomaria a $70{ }^{\circ} \mathrm{C}$ durante $20 \mathrm{~min}$. Em seguida, fez-se a centrifugação e rinsagem com água destilada. Esse procedimento foi repetido por 4 vezes. O tratamento com $\mathrm{HCl}$ foi feito para a remoção dos carbonatos.

Em seguida, foram adicionados $10 \mathrm{ml}$ de $\mathrm{H}_{2} \mathrm{O}_{2}$ a $15 \%$ para remoção de compostos orgânicos. Foram feitas 4 operações de rinsagem e centrifugação.
Finalmente, foi adicionado álcool etílico a $100 \%$ para a secagem do material (por $12 \mathrm{~h}$ ). Após esse processo obteve-se os fitólitos os quais foram armazenados em saquinhos plásticos para análises.

As amostras foram moídas e peneiradas para obter a fração fina $(>0,164 \mu \mathrm{m})$ e o material pulverizado obtido foi prensado com $\mathrm{H}_{3} \mathrm{BO}_{4}$ (FRX) e submetido a lixiviação com $\mathrm{H}_{2} \mathrm{O}$ e $\mathrm{HNO}_{3}$, diluído (para ICP OES).

\subsubsection{EXTRAÇÃO DE SI-FITÓLITOS NAS AMOSTRAS DE SOLO}

A extração dos Si-fitólitos das amostras de solos foi feita seguindo a metodologia desenvolvida por Kelly (1990) e modificada por Coe (2009). Antes da aplicação da metodologia para extração dos Si-fitólitos foi feita a secagem das amostras em estufa por 24 horas a $110^{\circ} \mathrm{C}$,

\subsubsection{TRABALHO EM LABORATÓRIO}

ANÁLISE TOTAL DOS SI-FITÓLITOS POR ICP OES

Os fitólitos foram pesados e dissolvidos com $\mathrm{HF} / \mathrm{HNO}_{3}$, conforme metodologia estabelecida no laboratório do NGqA do IGC da UFMG e submetido a leitura com equipamento de ICP OES - aparelho modelo M 4165 - Epectroflame - Spectro.

\section{ANÁLISES DAS AMOSTRAS DE SOLOS}

As amostras de solo/sedimento foram submetidas a dois tipos de análises: a) Leitura de composição total (FRX) e b) Leitura com ICP OES, após extração com

\section{ANÁLISE POR FRX}

A fração fina das amostras de solo foi prensada usando uma cera e lida por FRX em um equipamento Shimatzu no Laboratório Multiusuário - LIPEMVALE da UFVJM. A leitura foi feita em curvas

\section{ANÁLISE POR ICP OES}

Colocou-se $0,5 \mathrm{~g}$ da fração fina em tubos de Teflon, misturadas com $\mathrm{H}_{2} \mathrm{O}, \mathrm{HNO}_{3} 10 \%$ ou $\mathrm{HNO}_{3}$ concentrado e aquecidos em forno de micro-ondas da marca MARS-CEM segundo um programa SW-846-3051 estabelecido (US-EPA, 1998; CONAMA, e, posteriormente, $\mathrm{o}$ peneiramento $\mathrm{e}$ maceramento. Utilizou-se sempre uma alíquota de $20 \mathrm{~g}$ de solo seco. O resíduo, após dissolução é menor do que $0,01 \%$ e é formado por óxidos e outros compostos insolúveis existentes nas plantas.

As curvas foram calibradas com padrões internacionais (USGS; LGC; STMS) e do laboratório do NGqA do IGC da UFMG. Os dados das leituras são em ppm ou $\mu \mathrm{g}$ $\mathrm{mL}^{-1}$.

água, $\mathrm{HNO}_{3} \quad 10 \%$ e concentrado no laboratório de geoquímica ambiental do CPMTC-IGC-UFMG.

obtidas com padrões internacionais e internos. Os resultados são em \% para os elementos maiores e em $\mathrm{mg} \mathrm{kg}^{-1}$ para os elementos traços.

2009); após a extração o material foi filtrado e transferido para balões de $50 \mathrm{ml}$. A leitura foi feita em um equipamento ICP OES Marca SPECTRA em curvas estabelecidas com padrões internacionais e internas. Os resultados são disponibilizados em $\mathrm{mg} \mathrm{mL}^{-1}$. 


\subsection{TRATAMENTO DOS DADOS OBTIDOS}

A média e o desvio padrão foram calculados a partir das tabelas geradas pelo Programa Excel 2013 - Microsoft. Todos os dados com identificação específica de campo foram padronizados para os nove pontos de amostragem dos perfis. A distância entre os pontos de coleta e os

\section{RESULTADOS E DISCUSSÃO}

Os resultados são mostrados na forma de figuras, tabelas e diagramas com os pontos é $<4 \mathrm{~m}$. Esse valor é maior ou igual ao erro da determinação com GPS nos locais de amostragem no momento dos levantamentos. Estes dados tratados foram utilizados como base para os diagramas apresentados no trabalho.

\subsection{FORMAS DE FITÓLITOS ENCONTRADOS NAS ESPÉCIES ESTUDADAS}

A Figura 2 revela a aparência típica de Si-fitólitos dos extratos das plantas. Para a identificação dos morfotipos tomou-se como referência os trabalhos de Madella et al. (2005), Piperno (2006), Medeanic et al. (2007; 2008) e Lu et al. (2007). A forma mais encontrada foi a bilobate.

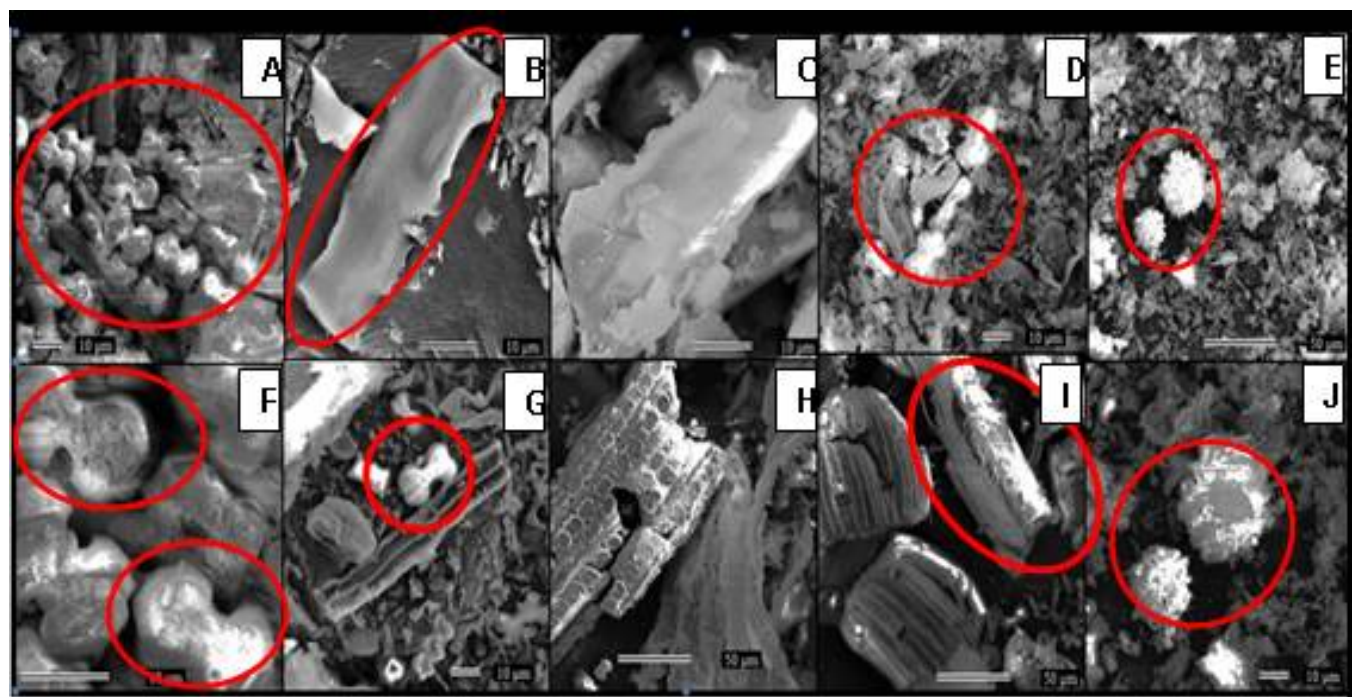

Figura 2: Microfotografias de algumas amostras de plantas com fitólitos. As fotografias mostram os diversos morfotipos observados. O estudo foi feito no Centro de Microanálise do Instituto de Geociências da UFMG. Legenda: $\mathrm{A}=$ bilobate, $\mathrm{B}=$ elongate, $\mathrm{C}=$ elongate, $\mathrm{D}=$ bilobate, $\mathrm{E}=$ globular granulate, $\mathrm{F}=$ bilobate, $\mathrm{G}=$ bilobate, $\mathrm{H}$ = não identificáveis, $\mathrm{I}=$ buliforme paralellipipedal, $\mathrm{J}=$ papillae.

\subsection{RELAÇÃO ENTRE O MATERIAL ORGÂNICO E FITÓLITOS}

Foram investigadas três diferentes espécies: Rollinia lepdoptella, Piptadenia gonoacantha e Sida sp, sendo que a Tabela 1 mostra a relação entre biomassa total e Si-fitólitos formados. A Rollinia lepdoptella foi a espécie que mais produziu Si-Fitólitos na planta (raízes, caules e folhas). Por outro lado, a Sida sp foi a espécie com maior quantidade de fitólitos nas folhas e a menor nas raízes, enquanto a Piptadenia gonoacantha foi a espécie com menor produção geral. Estas informações são importantes para orientar o uso e a aplicação dessas plantas em área contaminadas com metais pesados. 
Tabela 1: Relação entre peso seco, calculado de $1 \mathrm{~kg}$ e quantidade de Si-fitólitos.

\begin{tabular}{|c|c|c|c|c|c|}
\hline Planta & Órgão da planta & $\begin{array}{c}\text { Peso } 9880^{\circ} \mathrm{C} \text { média } \\
\text { pc }(\mathrm{g})\end{array}$ & $\begin{array}{c}\text { Relação } \\
\text { ps/pc(\%) }\end{array}$ & $\begin{array}{c}\text { Peso Fitólitos } \\
\text { pf média (g) }\end{array}$ & $\begin{array}{l}\text { Relação } \\
\text { ps/pf(\%) }\end{array}$ \\
\hline \multirow{2}{*}{$\begin{array}{c}\text { Rollinia } \\
\text { leptoptella }\end{array}$} & folha & 109,76 & 11,00 & 15,18 & 1,5 \\
\hline & raiz & 76,84 & 7,7 & 15,48 & 1,6 \\
\hline \multirow{2}{*}{$\begin{array}{l}\text { Piptadenia } \\
\text { gonoacantha }\end{array}$} & folha & 70,38 & 7,0 & 13,67 & 1,4 \\
\hline & caule & 74,98 & 7,5 & 8,62 & 0,9 \\
\hline \multirow{3}{*}{ Sida $s p$} & folha & 90,97 & 9,1 & 22,71 & 2,2 \\
\hline & caule & 98,86 & 9,9 & 16,39 & 1,7 \\
\hline & raiz & 85,75 & 8,6 & 7,71 & 0,8 \\
\hline
\end{tabular}

legenda: pc - peso calcinado; os - peso seco; pf - peso fitólitos.

\subsection{CONCENTRAÇÕES DE METAIS PESADOS NOS FITÓLITOS DAS PLANTAS.}

$\mathrm{Na}$ Tabela 2 são apresentadas as concentrações dos elementos selecionados em Si-fitólitos dos órgãos das plantas analisadas. Esta baixa relação ocorreu devido a uma limpeza minuciosa antes do procedimento de preparação dos fitólitos.

Observa-se claramente uma distribuição variada dos metais nos Si-fitólitos. A maior concentração ocorreu nos fitólitos extraídos das folhas, depois nos dos caules e finalmente daqueles provenientes das raízes. $\mathrm{Cd}$ mostra um comportamento diferente para Piptadenia gonoacantha in relação às outras plantas investigadas. The concentração é baixo nas raízes e mais alto nas folhas e caules. Precisa-se investigar mais a relação entre metabolismo das plantas e fatores físicos como $\mathrm{pH}$, concentração de água e outros elementos no solo.

Tabela 2: Concentrações médias $\left(\mathrm{mg} \mathrm{kg}^{-1}\right)$ de elementos químicos em Si-fitólitos nos órgãos (folhas, raízes e caules) das espécies Rollinia leptopetala, Sida sp e Piptadenia gonoacantha.

\begin{tabular}{|c|c|c|c|c|c|c|c|c|c|c|c|}
\hline Espécie & $\begin{array}{c}\text { Órgão } \\
\text { da } \\
\text { planta }\end{array}$ & $\mathbf{B a}$ & $\mathrm{Cr}$ & Co & $\mathbf{C u}$ & Cd & $\mathbf{N i}$ & $\mathbf{P b}$ & $\mathbf{T i}$ & Mn & Zn \\
\hline Rollinia & folha & 61021 & 49 & 293 & 6329 & 216 & 5434 & 1603 & 21886 & 112016 & 17171 \\
\hline Leptoptella & caule & 57943 & 2689 & 824 & 20911 & 357 & 9643 & 11244 & 312192 & 80589 & 16172 \\
\hline Bananinha & raiz & 27375 & 73 & 270 & 7550 & 200 & 1505 & 1627 & 16969 & 31358 & 34821 \\
\hline Piptadenia & folha & 37252 & 3291 & 726 & 8862 & 210 & 4044 & 2971 & 60569 & 148271 & 32811 \\
\hline Gonoacantha & caule & 8526 & 3352 & 580 & 3489 & 642 & 2563 & 3580 & 74659 & 37813 & 32670 \\
\hline Vassourinha & raiz & 90686 & 717 & 461 & 8785 & 182 & 2892 & 2061 & 26316 & 75980 & 32314 \\
\hline \multirow{3}{*}{$\begin{array}{c}\text { Sida sp } \\
\text { Pau jacaré }\end{array}$} & folha & 19788 & 193 & 157 & 5290 & 127 & 874 & 1825 & 8068 & 92732 & 22714 \\
\hline & caule & 32369 & 749 & 303 & 4192 & 108 & 1328 & 30546 & 53467 & 31172 & 14562 \\
\hline & raiz & 25721 & 116 & 618 & 8121 & 572 & 7499 & 3503 & 6040 & 118652 & 32214 \\
\hline
\end{tabular}

\subsection{CONCENTRAÇÕES DE METAIS PESADOS NO SOLO}

As amostras de solo analisadas dos nove pontos de coleta têm a distribuição conforme perfis mostrados na Figura 4. A sua distribuição é influenciada pela: morfologia, influência do vento, água a atividades humanas. Foram comparadas as concentrações totais de metais pesados do solo com testes de lixiviação de forças iôni cas diferentes.

Todas as três espécies concentram elementos traços em quantidades significativas nos Si-fitólitos nas folhas, existe, porém, uma variação entre as concentrações máximas encontradas nas três plantas e em seus diferentes órgãos (Tabela 3). 


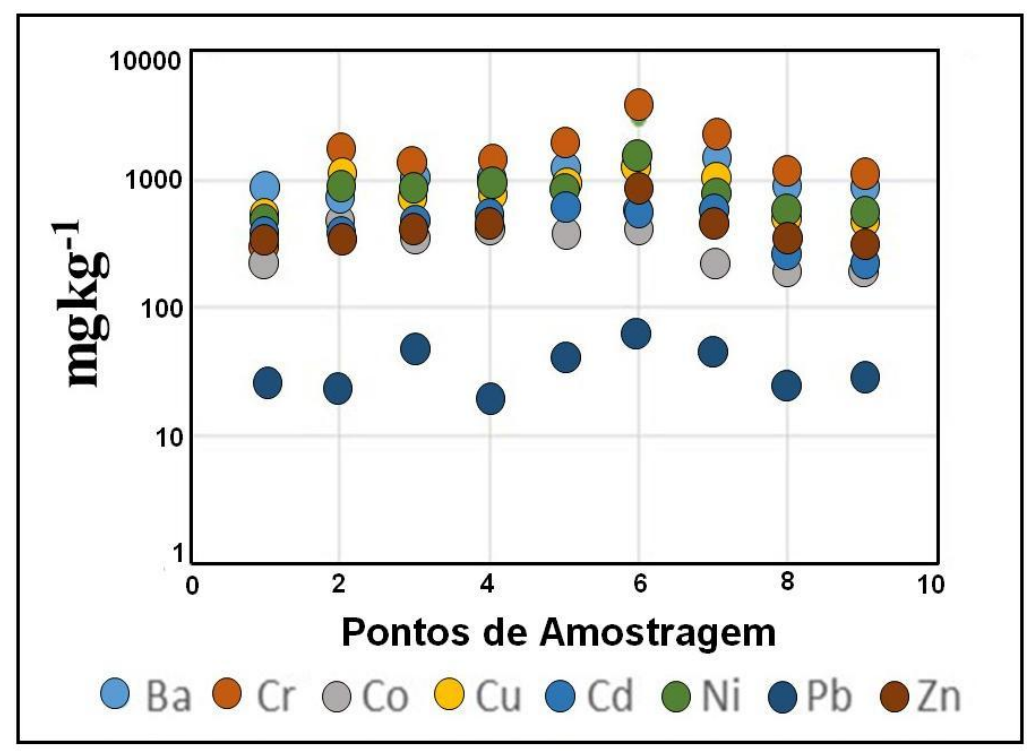

Figura 3

Distribuição dos elementos investigados nos pontos indicados nos mapas da Figura 1. As análises efetuadas mostraram boa correlação com a distribuição das concentrações em profundidade.

Tabela 3 - Relação entre espécies, órgãos das plantas e metais enriquecidos e concentrações atingidas

\begin{tabular}{|c|c|c|c|c|c|c|c|c|c|}
\hline \multirow[t]{2}{*}{ Espécie } & \multirow{2}{*}{$\begin{array}{c}\text { Órgão } \\
\text { da } \\
\text { planta }\end{array}$} & \multicolumn{4}{|c|}{$\begin{array}{l}\text { Concentração mínima em solos com } \\
\text { baixa concentração }\left(\mathrm{mg} \mathrm{kg}^{-1}\right)\end{array}$} & \multicolumn{4}{|c|}{$\begin{array}{l}\text { Concentração máxima em solos com } \\
\text { alta concentração }\left(\mathrm{mg} \mathrm{kg}^{-1}\right)\end{array}$} \\
\hline & & $\mathrm{Cu}$ & $\mathbf{P b}$ & $\mathrm{Zn}$ & Cd & $\mathrm{Cu}$ & $\mathbf{P b}$ & Zn & Cd \\
\hline \multirow{3}{*}{$\begin{array}{l}\text { Rollinia } \\
\text { Leptoptella }\end{array}$} & folha & 110 & 20 & 177 & 0,7 & 415 & 91 & 1323 & 6,4 \\
\hline & caule & 113 & 25 & 177 & 1,9 & 415 & 562 & 520 & 6,4 \\
\hline & raiz & 25 & 24 & 331 & 2,2 & 1046 & 562 & 809 & 22,9 \\
\hline \multirow{3}{*}{$\begin{array}{l}\text { Piptadenia } \\
\text { Gonoacantha }\end{array}$} & folha & 41 & 17 & 211 & 0,5 & 315 & 415 & 1168 & 28,6 \\
\hline & caule & 127 & 16 & 442 & 0,5 & 406 & 283 & 1610 & 28,6 \\
\hline & raiz & 120 & 16 & 120 & 2,5 & 139 & 48 & 364 & 5,4 \\
\hline \multirow{3}{*}{$\begin{array}{l}\text { Sida sp } \\
\text { Pau jacaré }\end{array}$} & folha & 221 & 17 & 212 & 2,3 & 443 & 112 & 1641 & 11 \\
\hline & caule & 81 & 81 & 275 & 0,7 & 439 & 773 & 1615 & 5,9 \\
\hline & raiz & 174 & 174 & 481 & 0,6 & 315 & 85 & 1634 & 32 \\
\hline
\end{tabular}

Na espécie Rollinia leptoptella, o Zn se enriqueceu principalmente nas folhas e em menor grau no caule e nas raízes. $\mathrm{O} \mathrm{Pb}$ concentrou-se mais no caule e nas folhas, enquanto o $\mathrm{Cu}$ ficou mais concentrado no caule e nas raízes. Pode-se inferir que a saturação desses fitólitos ocorreu em torno de $100 \mathrm{mg} \mathrm{kg}^{-1}$ de metal, com a exceção do caule que concentrou o $\mathrm{Cu}$ até aproximadamente $1.000 \mathrm{mg} \mathrm{kg}$. A Piptadenia gonoacantha enriqueceu quantidades maiores de metais do que a Rollinia leptopetala (Tabelas 1 e 2 ). Principalmente $\mathrm{o}$ caule $\mathrm{e}$ as folhas concentraram $\mathrm{Cu}, \mathrm{Zn}$ e $\mathrm{Pb}$. As raízes mostraram teores semelhantes aos da espécie Rollinia leptopetala. A espécie Sida sp. concentrou quantidades maiores de $\mathrm{Zn}, \mathrm{Cu}$ e $\mathrm{Pb}$ nas raízes (Tabela 2). As concentrações máximas encontradas foram bem semelhantes às da espécie Piptadenia gonoacantha e bem mais altas do que as da espécie Rollinia leptopetala. Observa-se que o aumento desses elementos nos $\mathrm{Si}$ fitólitos ocorreu conforme as concentrações encontradas no solo.

As amostras de caule mostraram em geral concentrações intermediárias e as das folhas, altas concentrações, o que era de se esperar devido ao fato dessa última ser o ponto final do transporte dos fluídos com elementos. Geralmente ocorre das raízes até às folhas uma redução da concentração dos elementos no líquido devido à redução do seu volume, o que é refletido nas concentrações de metais encontradas nos Si-fitólitos.Variações atípicas nas concentrações podem ser um efeito da competição entre os elementos na interação com o $\mathrm{SiO}_{2}$ e também de processos metabólicos das plantas e interações da superfície das raízes com o solo. 


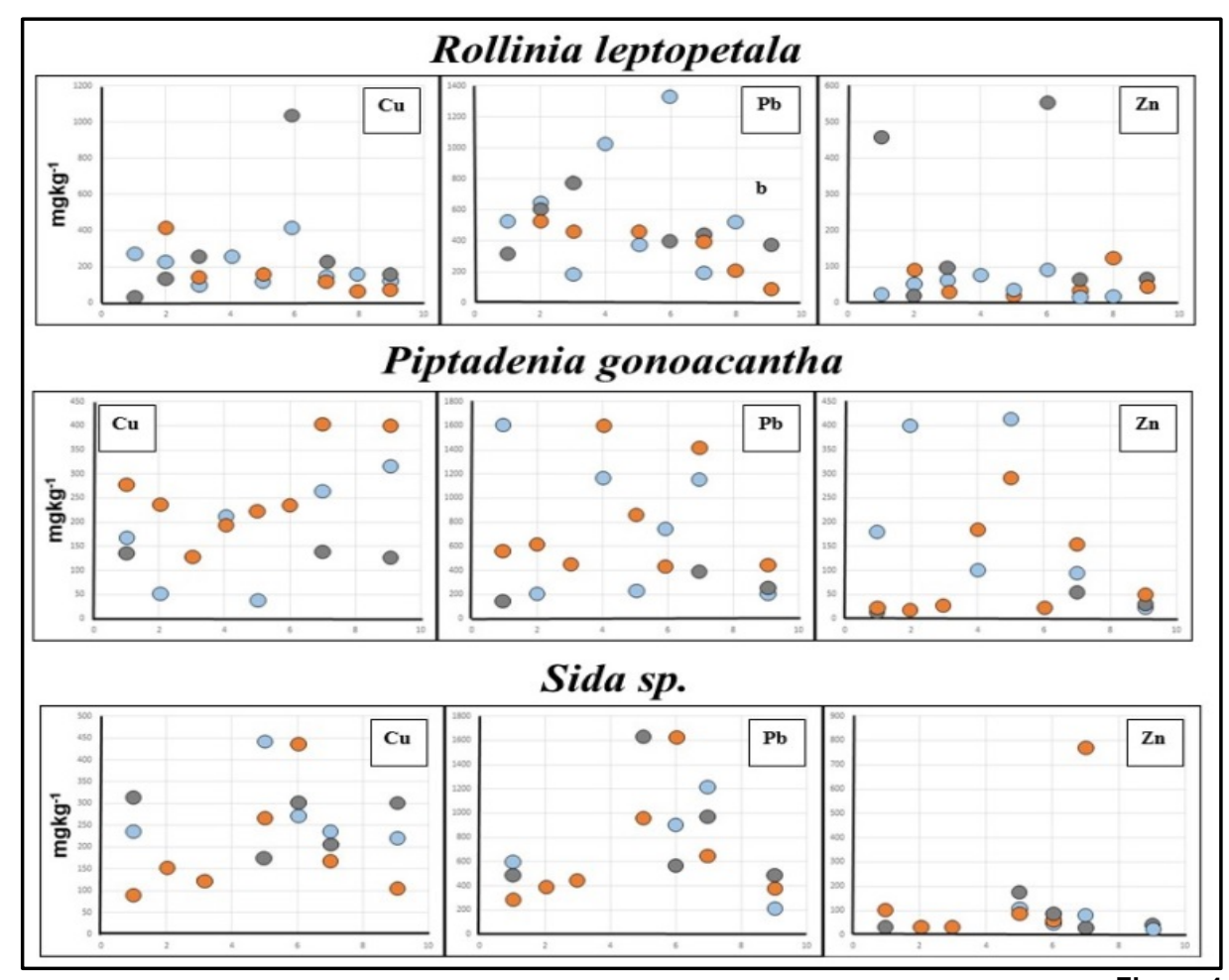

Distribuição dos metais selecionados ( $\mathrm{Cu}, \mathrm{Pb}$ e $\mathrm{Zn}$ ) nas espécies Rollinia leptopetala (azul), Piptadenia gonoacantha (marrom) e Sida sp. (cinza)

$\mathrm{Na} \quad$ Figura 4 observa-se as concentrações de $\mathrm{Cu}, \mathrm{Zn}$ e $\mathrm{Pb}$ nos Sifitólitos dos diferentes órgãos das espécies selecionadas. Nas folhas, os teores dos elementos chegaram no máximo a 400-450 $\mathrm{mg} \mathrm{kg}^{-1}$ e normalmente entre 50 e 300 $\mathrm{mg} \mathrm{kg}^{-1}$. As concentrações dos Si-fitólitos extraídos dos caules atingiram normalmente $100-300 \mathrm{mg} \mathrm{kg}^{-1}$, com concentrações máximas de 400-1.600 $\mathrm{mg} \mathrm{kg}^{-1}$. Nas raízes, as concentrações dos metais variaram de 50 a $300 \mathrm{mg} \mathrm{kg}^{-1}$, com concentrações altas chegando até 500$1.800 \mathrm{mg} \mathrm{kg}^{-1}$ em áreas com anomalias. $\mathrm{O}$ $\mathrm{Zn}$ teve concentrações de até $500 \mathrm{mg} \mathrm{kg}^{-1}$.

\subsection{CONCENTRAÇÕES DE METAIS PESADOS NOS SI-FITÓLITOS NOS SOLOS}

Pela aparência e composição similares e posicionamento da amostragem, pode-se considerar que os fitólitos no solo pertençam principalmente às plantas coletadas ali (Tabela 4). Essas concentrações semelhantes mostram que os metais pesados permanecem estáveis nestas partículas e não são introduzidos no solo na forma disponível.

\subsection{DISPONIBILIDADE DOS METAIS SELECIONADOS PARA AS PLANTAS EM COMPARAÇÃO COM AS CONCENTRAÇÕES DOS SI-FITÓLITOS DAS PLANTAS}

Pode-se observar que as concentrações disponíveis de metais pesados (solúvel em água/ácido fraco) diminuem com o aumento da concentração desses elementos nos Si-fitólitos extraídos (Figura 6).
A variação das concentrações, seja nas amostras do solo ou nos Si-fitólitos das plantas, se comportam semelhantemente. Os resultados das espécies Sida sp. e Rollinia leptopedela, indicam mais fielmente as anomalias da área. 


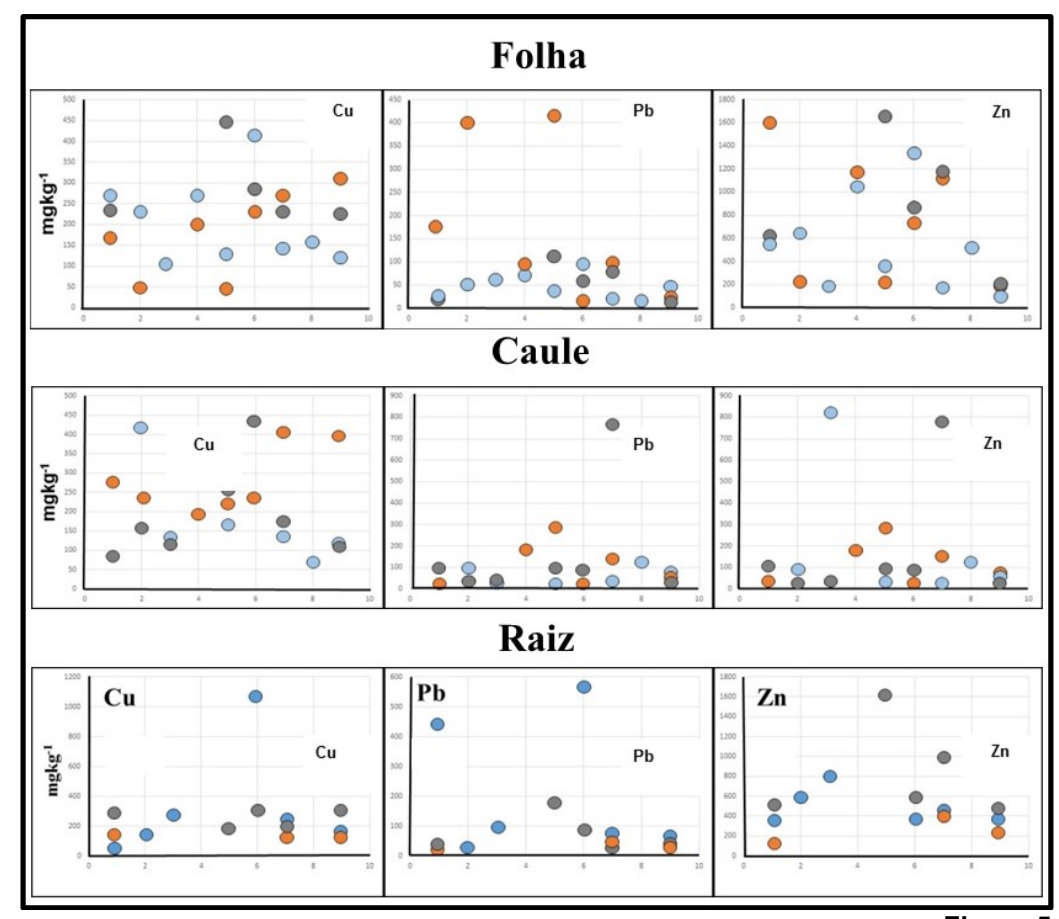

Figura 5

Distribuição de $\mathrm{Cu}, \mathrm{Pb}$ e Zn nos órgãos das espécies Rollinia leptopetala (azul), Piptadenia gonoacantha (marrom) e Sida sp.

(cinza).

Tabela 4 Concentrações de metais $\left(\mathrm{mg} \mathrm{kg}^{-1}\right)$ em Si-fitólitos coletados na área de estudo.

\begin{tabular}{|c|c|c|c|c|c|c|c|c|c|c|}
\hline \multirow{2}{*}{$\begin{array}{c}\text { Amostras de Si } \\
\text { Fitólitos em solo }\end{array}$} & \multicolumn{2}{|c|}{$\mathrm{Cr}$} & \multicolumn{2}{|c|}{$\mathrm{Cu}$} & \multicolumn{2}{|c|}{ Zn } & \multicolumn{2}{|c|}{$\mathbf{B a}$} & \multicolumn{2}{|c|}{$\mathbf{P b}$} \\
\hline & $\min$ & $\max$ & $\min$ & $\max$ & $\min$ & $\max$ & $\min$ & $\max$ & $\min$ & $\max$ \\
\hline $\begin{array}{l}\text { Local de baixa } \\
\text { concentracão }\end{array}$ & 0,17 & 3,5 & 0,16 & 0,17 & 17,4 & 27 & 24 & 184,0 & 1,2 & 3,6 \\
\hline $\begin{array}{l}\text { Local de alta } \\
\text { concentração }\end{array}$ & 4,5 & 15,2 & 0,9 & 1,9 & 13,4 & 76,6 & 178,3 & 1362,9 & 3,6 & 16,7 \\
\hline
\end{tabular}
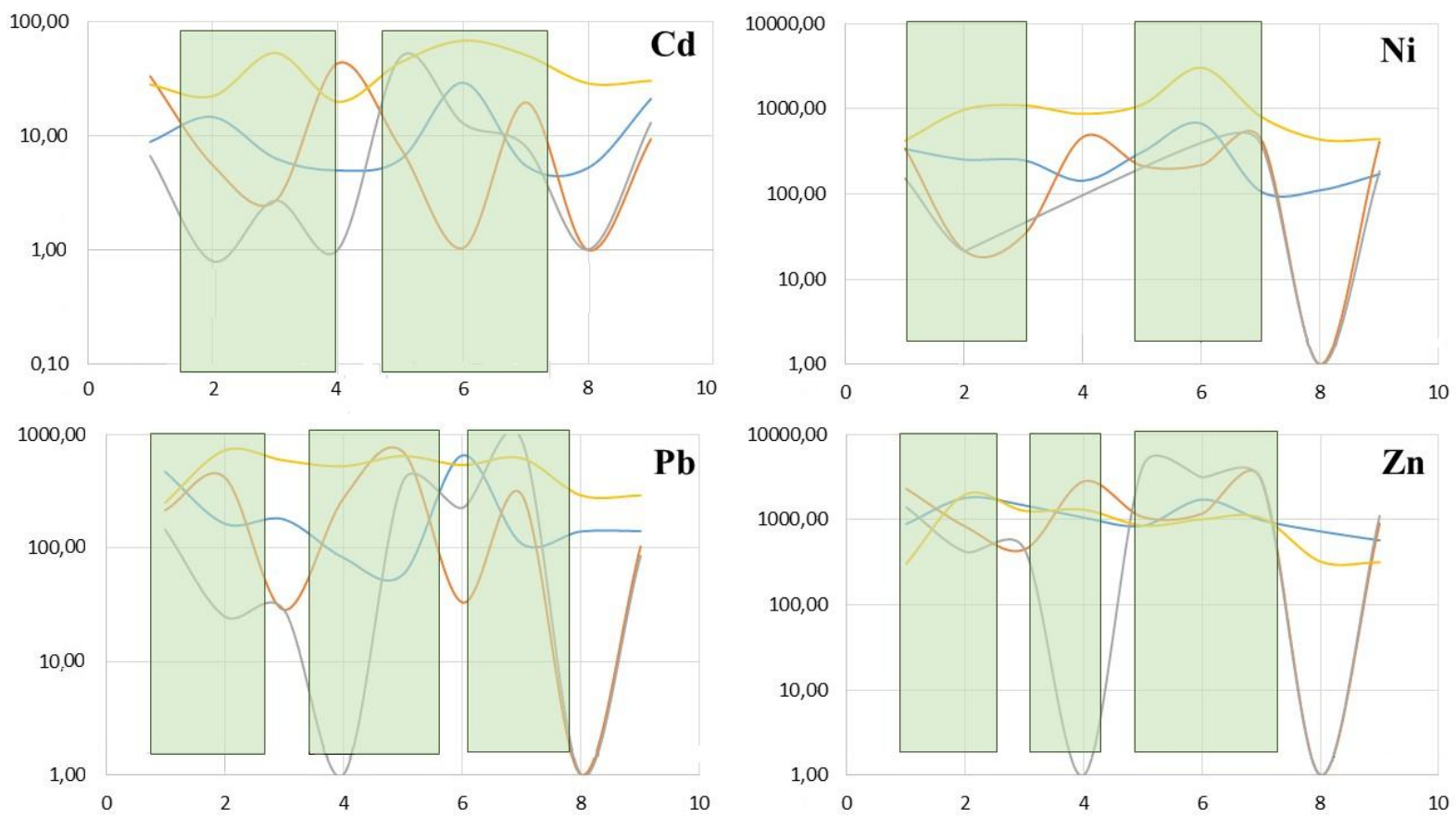

Figura 6

Relação da concentração de metais selecionados ( $\mathrm{Ba}, \mathrm{Cr}$, $\mathrm{Co}, \mathrm{Cu}, \mathrm{Cd}, \mathrm{Ni}, \mathrm{Pb}$ e $\mathrm{Zn}$ ) em amostras do solo e amostras dos fitólitos das plantas (concentração média das plantas). As concentraç̃es em solo são os resultados de análises com FRX. Os pontos 2, 5, 6 e 7 representam as anomalias indicadas nos mapas de isolinhas de teores de $\mathrm{Cu}, \mathrm{Zn}$ e $\mathrm{Pb}$. Linhas: azul - Rollinia Leptopetala; laranja - Piptadenia Gonoacantha; cinza - Sida sp; amarela - Solo. 


\section{CONCLUSÕES}

Baseando-se nos resultados obtidos, conclui-se que as espécies como Sida sp, Rollinia leptopetala e Piptadenia gonoacantha podem ser utilizadas para reduzir a concentração e disponibilidade de metais pesados do solo.

a. As plantas estudadas neste trabalho sintetizam quantidades significativamente altas de $\mathrm{Si}$ fitólitos em todos os órgãos investigados;

b. Elas concentram metais em quantidades altas nos Si-fitólitos;

c. As plantas selecionadas fazem parte do bioma (Cerrado) e estão altamente adaptadas às condições adversas (baixa fertilidade do solo) e resistem a condições extremas (déficit hídrico prolongado);

\section{AGRADECIMENTOS}

Agradecemos a CAPES pela bolsa, a PRPq/UFMG e UVJM pelo apoio logístico

\section{REFERÊNCIAS BIBLIOGRÁFICAS}

COE, H. H. G. Fitólitos como indicadores de mudanças na vegetação xeromórfica da região de Búzios/Cabo frio, RJ, durante o Quaternário. Rio de Janeiro: Univ. Fed. Fluminense. 340p. (Progr. Pós-Grad. Geologia e Geofísica Marinha, Tese Dout.). 2009.

CONAMA - Conselho Nacional de Meio Ambiente Resolução $\mathrm{n}^{\circ} 420$ de 28 de dezembro de 2009. Diário Oficial da União $\mathrm{n}^{\circ} 249$, de 30 de dezembro de 2009, 81-84, 2009

EMBRAPA - Empresa Brasileira de Agropecuária Serviço Nacional de Levantamento e Conservação de Solos. Mapeamento de Solos e Aptidão Agrícola das Terras do Estado de Minas Gerais. Rio de Janeiro: Embrapa Solos. (Boletim de Pesquisa e Desenvolvimento, 63), 95p. 2004

EMBRAPA - Empresa Brasileira de Agropecuária Centro Nacional de Pesquisa do Solo. Sistema brasileiro de classificação de solos. 2. ed. Rio de Janeiro: Embrapa Solos, 306 p. 2006 d. Os diferentes Si-fitólitos das plantas e dos órgãos concentram os metais selecionados em quantidades diferentes. Este fato deve ocorrer em função da variação de concentrações na planta durante a formação delas;

e. Os Si-fitólitos das amostras de solo apresentam concentrações de metais semelhantes àquelas encontradas nos Sílico-fitólitos;

f. A solubilidade dos Sílico-fitólitos em condições de solos do Cerrado é muito baixa, o que permite boa estabilidade por grandes períodos de tempo $\left(>10^{4}\right.$ anos).

Todos estes fatores permitem e sugerem o uso das plantas investigadas para a redução de metais disponíveis em áreas contaminadas.

e a Empresa Mineração Carpathian Gold Ltda. pelo fornecimento de dados.

FERNANDES-HORN, H. M.; SAMPAIO, R. A.; HORN, A. H.; OLIVEIRA, E. S. A. DE; LEPSCH, I.G.; BILAL, E.. Use of Si-Phytoliths in depollution of mining areas in the Cerrado-Caatinga Region, MG, Brazil. Intern. Journal of Geomate. 11(23), 2216-2221, 2016

IBGE-Instituto Brasileiro de Geografia Estatística Cidades@.Informações sobre os municípios brasileiros. Disponível em: <www.ibge.gov.br>. Acesso em: 25 ago. 2015.

JONES, L. H. P.; HANDRECK, K. A. Silica in soils, plants and animals. Adv. Agron. 19, 107-149, 1967

LIMA, I. L. P.; MEDEIROS, M. B.; SEVILHA, A. C. Diversidade e uso de plantas do Cerrado em comunidade de Geraizeiros no norte do estado de Minas Gerais, Brasil. Acta Botânica Brasílica, 26(3), 675-684, 2012

MADELLA, M.; ALEXANDRE, A.; BALL $T$. International code for phytolith nomenclature 1.0. Annals of Botany, 96(2), 253-260, 2005 
MEDEANIC, S.; DILLENBURG, S. R.; WESCHENFELDER, J. Palinomorfos nos sedimentos de fundo de laguna dos Patos, RS: Aplicação nas reconstruções paleoambientais. Gravel, 5(1), 89-102, 2007

MEDEANIC, S.; CORDAZZO, C. V.; CORRÊA, I. C. S.; MIRLEAN, N. Os fitólitos em Gramíneas de Dunas do Extremo Sul do Brasil: variabilidade morfológica e importância nas reconstruções paleoambientais costeiras. Gravel, 6(2), 1-14. 2008

LU, H. Y.; WU, N. Q.; LIU, K. B.; JIANG, H.; LIU, T. S. Phytoliths as quantitative indicators for the reconstruction of past environmental conditions in China II: Palaeoenvironmental reconstruction in the loess plateau. Quaternary Science Reviews, 26(5), 759-772, 2007

PARR, J. F.; LENTFER, C. J.; BOYD, W. E. A comparative analysis of wet and dry ashing techniques for the extraction of fitólitos from plant material. Journal of Archaeological Science, 28, 875-886. 2001

PIPERNO, D. R. Phytoliths: a comprehensive guide for archaeologists and paleoecologists. Rio de Janeiro, Alta Mira Press. 238p. 2006

PIPERNO, D. R.; PEARSALL, D. M. Phytoliths in the reproductive structures of Maize and Teosinte: implications for the study of Maize evolution. Journal of Archaeological Science, 20, 337-362, 1993

STEWART, W. D.; ARTHUR, J. M. An improved standardized method for ashing of plant material. American Journal of Botany, 22, 905-925, 1935

US-EPA (1998). Method 3051. Disponível em: http://www.epa.gov/SW-

846/3051.pdf. Acesso em: mar. 2014. 